\title{
LA COMUNICACIÓN INSTITUCIONAL ANTE EL RETO DE LA RESPONSABILIDAD SOCIAL
}

THE INSTITUTIONAL COMMUNICATION TO THE CHALLENGE OF THE SOCIAL RESPONSIBILITY

\author{
Madrigal Barrón, Patricia ${ }^{1}$ \\ Universidad Rey Juan Carlos de Madrid (España) \\ patricia.madrigal@urjc.es
}

Material original autorizado para su primera publicación en la revista académica REDMARKA. Revista Digital de Marketing Aplicado.

https://doi.org/10.17979/redma.2013.01.011.4804

Recibido: 15 Octubre 2013

Aceptado 3 Diciembre 2013

\section{Resumen}

\footnotetext{
1 Licenciada en Economía, Premio Extraordinario Fin de Carrera, y Máster en Gestión e Investigación de la Comunicación Empresarial por la Universidad Rey Juan Carlos (URJC).

Profesora en el Departamento de Ciencias Sociales de la URJC. Colabora en la dirección del Máster Universitario en Gestión e Investigación de la Comunicación Empresarial de la URJC, siendo, además, la coordinadora de "Prácticas Externas" de dicho Máster.

Ha participado en diversos proyectos de investigación a nivel nacional e internacional. Sus líneas de investigación se centran en estudios de comunicación organizacional, empresa, discapacidad y empleo.

Es miembro activo de la Asociación Castellano-Manchega de Sociología y del Grupo de Investigaciones y Estudios Sociales Avanzados. Asimismo, a lo largo de su trayectoria académica y profesional, ha colaborado con varios grupos de investigación, entre otros, el Grupo de Investigación Visual.
} 
El mundo está cambiando. Las instituciones operan en un entorno de transformación, que las obliga a estar en constante adaptación. Este texto estudia una de esas transformaciones, el creciente papel de la Responsabilidad Social Corporativa, y pretende ayudar a las instituciones en los nuevos escenarios. De la Responsabilidad Social Corporativa (RSC) nos centraremos en la labor que ha de desempeñar la comunicación. Estudiaremos una entidad de éxito en materia de comunicación de su RSC, como ejemplo de ayuda para las instituciones en su necesidad de adaptación a los nuevos tiempos.

\section{Palabras clave}

Responsabilidad Social Corporativa, Comunicación, Buenas prácticas

\section{Abstract}

The world is changing. The institutions carry out tasks in an environment of transformation, which requires them to be in constant adaptation. This paper analyses one of these transformations, the growing role of the Corporate Social Responsibility, and it pretends to help to the institutions in the changes in matters of communication. For this, it examines an entity with success, as example of adaptation to new times.

\section{Key words}

Corporate social responsibility, Communication, Good practices 


\section{Introducción}

Nada es hoy igual a ayer. El mundo en el que vivimos se ha visto inmerso en un proceso de transformación de fuerte intensidad en las últimas décadas. Ante las transformaciones vividas, hay un reto de adaptación. Se hace necesario estar presente en un mundo evolucionado $y$, sobre todo, es imprescindible saber gestionar esas nuevas coyunturas que se presentan.

Las instituciones tienen un papel fundamental en las sociedades en las que se asientan. Ante las transformaciones habidas se enfrentan a un panorama poliédrico; son parte de las alteraciones, se ven afectadas por ellas, son responsables de las mismas y deben saber incluir esas vicisitudes en su modelo de gestión.

La creciente influencia de la sociedad y las personas que la forman en la estrategia institucional, es uno de los importantes cambios acontecidos en los últimos años. Por ello, se intensifica el deber de las instituciones ante las demandas sociales, las cuáles deben ser asumidas en una gestión no al margen de las mismas.

Las instituciones aumentan sus responsabilidades en una triple cuenta de resultados de objetivos económicos, sociales y medioambientales. La integración voluntaria de preocupaciones económicas, sociales y medioambientales en la gestión de las entidades, es un modelo de pensamiento denominado Responsabilidad Social Corporativa (RSC).

En la actualidad, la RSC es un factor clave en las entidades. Un concepto que comienza a ser un habitual en los discursos estratégicos. Cada vez más, las entidades deben asumir su responsabilidad social. Los grupos de interés demandan ese compromiso y las entidades no pueden estar ausentes, su gestión se resentiría si lo hicieran, sería una demostración de sus dificultades de adaptación a los cambios, lo que tendría influencias trascendentales en su desarrollo organizativo.

La comunicación juega un papel fundamental en la Responsabilidad Social Corporativa. De nada sirve que las entidades integren en su modelo 
preocupaciones económicas, sociales y medioambientales, demandadas por sus grupos de influencia, si estos grupos no reciben esa información. La población debe conocer las acciones de RSC que llevan a cabo las entidades con las que se relacionan. Se deberá hacer uso de herramientas comunicativas para conseguir ese fin. Las entidades deberán conocer las posibles herramientas con las que poder contar en esa labor y deberán desarrollar campañas de comunicación proclives a la difusión de sus acciones en materia económica, social y medioambiental.

El presente texto tiene como objetivo estudiar la Responsabilidad Social Corporativa desde el papel que juega la comunicación. La primera parte versa sobre el concepto de RSC, en un intento de concienciar a las instituciones de la importancia que tiene hoy integrar esas preocupaciones de triple vertiente, haciendo especial énfasis en resaltar el valor de la comunicación. Concienciadas las instituciones, éstas deben aprender a desarrollar las labores de responsabilidad. En ese aprendizaje el ejemplo es una figura clave. Por eso, la segunda parte de este texto será un análisis de una entidad de peso en términos de Responsabilidad Social Corporativa, examinando las herramientas que utiliza para la comunicación con sus grupos de interés demandantes, en imagen de lo que deben hacer las entidades para vivir en un mundo de cambio que es el suyo, pero sobre todo deber ser suyo, por su adaptación al mismo.

\section{La Responsabilidad Social Corporativa}

La Responsabilidad Social Corporativa es un modelo de pensamiento desarrollado en la segunda mitad del siglo XX. "En los años ochenta, y como consecuencia de la crisis de los setenta, se deja de pensar en el Estado como único administrador del gasto social y responsable de la contención de desigualdades y se comienza a defender la idea de que la contribución al bienestar y a la calidad de vida debe ser la meta de todos las instituciones sociales" (Cuesta y Valor, 2003: 7). El bienestar total de la sociedad se 
comienza a percibir como un alcance en términos máximos si confluyen diferentes fuerzas.

La Comisión Europea (2001: 7) define la RSC como la integración voluntaria, por parte de las entidades, de las preocupaciones sociales y medioambientales en sus actuaciones y sus relaciones con sus interlocutores.

En la actualidad, las instituciones deben tener en cuenta su responsabilidad social hacia el entorno que les rodea, respetando ciertas reglas y desarrollando determinadas actividades a favor del conjunto de la sociedad. La responsabilidad de las entidades con el entorno en el que actúan no se limita a la generación de riqueza y empleo en la zona, incluye, también, la realización o promoción de actividades de interés social, contemplando su aproximación a la "Triple cuenta de resultados": responsabilidad económica, responsabilidad social y responsabilidad medioambiental. La responsabilidad económica supone alcanzar un mayor bienestar económico; sostenibilidad, crecimiento económico, pleno empleo, estabilidad de precios, etc. La responsabilidad social abarca actitudes de desarrollo de la educación y la cultura, protección a las personas con discapacidad y mejoras sanitarias, entre otras acciones de interés para la sociedad. La defensa del medio ambiente se engloba en la responsabilidad medioambiental.

La Responsabilidad Social Corporativa es un activo intangible, de generación de beneficios, pero no solo en los términos económicos que solemos asociar a la noción de resultados. Si algo ha cambiado definitivamente en el modelo organizativo actual, es la transformación del concepto de beneficios. Estos se alejan de su definición monetaria e introducen una serie de factores que aportan un valor sustancial incalculable en términos numéricos por su ausencia de equivalente en números y por su sustancioso poder.

Las acciones de RSC "consisten en ayudar de forma voluntaria a que se cumplan las expectativas de la sociedad, para que ésta comprenda que los objetivos de la organización van más allá de los meramente lucrativos. Lo que genera imagen para la organización y reconocimiento en sus públicos, por el esfuerzo realizado." (Marín, 2008: 14). El compromiso social de las 
instituciones es un factor esencial de estrategia. Este factor ayuda a alcanzar una imagen de valores simbólicos asociada a los productos $y / 0$ servicios proporcionados por la entidad. La Responsabilidad Social Corporativa es rentable social y económicamente, y consigue que las personas trabajen más motivadas, fidelidad y stakeholders con mayor grado de satisfacción. Cada vez más conseguir éxito va unido a la capacidad de las entidades para adaptarse a la sociedad.

Una capacidad de adaptación que va unida a la de comunicación. Comunicación con los grupos de interés, manteniendo un diálogo permanente y fluido con ellos con el objetivo de conocer sus demandas y poder cumplirlas. Al tiempo que satisface esas expectativas de los grupos de interés, la institución debe comunicar adecuadamente su orientación responsable, con el fin de que la sociedad conozca esa disposición y sea capaz de asociar a la entidad unos valores necesarios en su desarrollo organizacional

Por la importancia de la comunicación en las prácticas de RSC, muchos defienden que sea el departamento de comunicación el que tenga asociado esas funciones. Uno de los defensores es Benito Castro, quien en su libro El auge de la comunicación corporativa expresa lo siguiente:

"Considero que la Responsabilidad Social Corporativa es una tarea a incluir entre las que desarrollan los departamentos de Comunicación Corporativa. Existen varias razones que avalan esto. La primera es que, cuando hablamos de Responsabilidad Social Corporativa, efectivamente nos referimos a intangibles; es decir, la misma materia prima con la que trabaja la Comunicación Corporativa.

En segundo lugar, la Responsabilidad Social Corporativa se concreta en la ejecución de tareas que no tendrían valor alguno si no se comunicaran. $Y$ en tercer lugar, aunque la Comunicación Corporativa tiene un evidente déficit en cuanto a su consolidación en las órbitas de las organizaciones, posee sin embargo una 
extensión y un conocimiento suficientes como para poder llevar adelante todo lo relativo a la Responsabilidad Social Corporativa, antes que ningún otro departamento." (Castro: 2007, 84).

Estas palabras respaldan la relevancia de la comunicación. De nada sirven las acciones de Responsabilidad Social Corporativa si los agentes a las que van destinadas no tienen conocimiento de las mismas. Por eso, es fundamental que las instituciones se conciencien de ello y desarrollen las herramientas necesarias para dar a conocer su RSC.

En esa concienciación y ese desarrollo de acciones, el aprendizaje adquirido de los ejemplos de otros es fundamental. En el mundo competitivo en el que vivimos, son variadas las ocasiones en las que parece que el conocimiento es exclusivo, un nicho propio al que los demás no deben tener acceso, porque perderemos valor. El conocimiento es nuestro y solo nuestro, tenemos miedo de difundir más de lo debido. Estos planteamientos son erróneos, el valor se pierde cuando no hay una puesta en común. Se hace necesario un cambio de paradigma para conseguir las bases de una comunidad creadora en conjunto, en la que todos seamos parte, todos proporcionemos y todos obtengamos del resto conocimiento a desarrollar. En esa premisa se basan las líneas siguientes de este texto.

\section{El ejemplo como factor de comunidad y de estrategia}

En relación a esa puesta en común imprescindible hay que recordar que el ser humano es un ser un social, empíricamente no es posible hallar seres humanos aislados. Hanifan, destacado sociólogo estudioso de los comportamientos en comunidad y del capital social de las comunidades, decía que el individuo por si solo es indefenso, lo que le lleva a crear redes entre sus iguales para hacer frente a los problemas sociales, económicos, políticos, etc. La creación de comunidades para hacer frente a las dificultades conduce a la construcción de redes para vivir, todo en la vida, hasta el hecho más insignificante, se hace en 
común. Nuestras redes nos influyen en nuestro día a día. Vivimos en un contexto en el que el conjunto nos afecta, somos comunidades, no podemos vivir solos. (Putnam, 2003). Estas redes que se crean son modo de relación, modo de hacer frente a los problemas y modo de aprendizaje. De la comunidad aprendemos y es necesario fomentar ese aprendizaje, en el que ha de destacar la enseñanza en red, los unos con los otros y, también, los unos de los otros.

Para sustentar la importancia del conocimiento en red, nos sirve el Libro Verde sobre Responsabilidad Social Corporativa de la Comisión Europea, que en su punto 4 hace alusión a la necesidad de dar a conocer mejor la RSC y facilitar el intercambio de experiencias y de buenas prácticas. El siguiente párrafo ha sido extraído de ese punto cuarto por seguir la línea de lo que venimos tratando aquí en relación al intercambio de enseñanzas. Aunque se centra en la empresa y en su Responsabilidad Social Empresarial (RSE), no en el ámbito más institucional, es interesante su lectura como afianzamiento de la defensa hecha.

"En sus respuestas al Libro Verde, las organizaciones patronales y las empresas individuales subrayaron la importancia que reviste el intercambio de experiencias y de buenas prácticas en materia de responsabilidad social como medio fundamental para profundizar en la definición del concepto, ya que permitiría a las empresas familiarizarse con el mismo, comparar su situación con la de sus competidores y lograr un consenso sobre los instrumentos que deben utilizarse, tales como las normas para la elaboración de informes y los procedimientos de verificación. Estos intercambios podrían resultar especialmente útiles a nivel sectorial, ya que contribuirían significativamente a definir los desafíos comunes y las posibilidades de cooperación entre competidores. Dicha cooperación permitiría reducir los costes derivados de la adopción de prácticas de responsabilidad social y 
contribuiría a garantizar unas reglas de juego equitativas." (Comisión europea: 2001: 11).

Bajo estas ideas se ha desarrollado un análisis de las herramientas comunicativas que utiliza una entidad concreta en la difusión de sus prácticas de Responsabilidad Social Corporativa, como puesta en común de un ejemplo del que aprender. En un intento de cumplir esa premisa de vivir el conocimiento en comunidad.

Para la elección de la entidad a usar como ejemplo, se ha acudido al país líder en el tema de responsabilidad social, Suecia. En este campo, "Suecia está haciendo más que la mayoría y eso, desde hace tiempo. En el 2007, en el informe final sobre el Estado de la Competitividad Responsable elaborado por la organización internacional no lucrativa AccountAbility, Suecia ocupó el puesto más alto del Índice de Competitividad Responsable." (Swedish Institute, 2011: 1). En palabras del el Dr. Simon Zadek, jefe ejecutivo de AccountAbility:

"el modo sueco de hacer negocios responsables, impresiona, y para bien, pues la CSR ha sido adoptada por las empresas suecas, desde las industrias de la confección hasta las industrias pesadas. Dicho de otra forma, los suecos saben cómo hacer negocios teniendo en cuenta al mismo tiempo el cambio climático, las cuestiones de género, los derechos humanos y la política contra la corrupción." (Cámara de Comercio Sueco Argentina, 2010: 1). [CSR- Corporate Social Responsibility].

La empresa insignia de este país nórdico es IKEA, por ello ha sido la elegida para el análisis que se presenta a continuación. IKEA es una empresa dedicada a la venta de productos para la decoración del hogar caracterizados por su funcionalidad, buen diseño y precios reducidos. La empresa es considerada una de las más prestigiosas e innovadoras, con un exitoso modelo de negocio estudiado en las escuelas de negocios. IKEA transformó el modelo 
de fabricación y comercialización de mobiliario de manera que la mayoría de muebles que vende son desarmables, embalados en paquetes planos y automontables. Su línea de productos abarca todas las necesidades del hogar. Las tiendas cuentan con la exposición de muebles, en la que los clientes pueden tocar y probar los productos, los cuáles están identificados con un nombre y un código para facilitar su búsqueda en la zona de autoservicio, donde podrán ser adquiridos por el cliente, disponiendo de ellos el mismo día que los compra. Algunas de las tiendas IKEA cuentan con una zona de oportunidades, en la que se venden productos levemente dañados a precios bajos, y la mayoría disponen de restaurante y tienda de productos alimenticios suecos. IKEA es diferente, inspiración, inmediatez, calidad y precios asequibles son cuatro palabras que definen el negocio. (Kamprad, I. y Torekull, B., 2008).

IKEA desarrolla importantes acciones de Responsabilidad Social Corporativa, para que éstas lleguen a sus grupos de interés hace uso de diferentes herramientas de gestión de la percepción social, con el fin de que su logotipo azul y amarillo (colores de la bandera sueca) represente unos valores simbólicos de apreciación social. Entre los instrumentos que utiliza se encuentran la página web, los catálogos y folletos, los anuncios televisivos, las tiendas y las redes sociales. Como ejemplo para las instituciones de estrategia comunicativa de éxito, estudiaremos una por una esas herramientas.

\section{Página web de IKEA}

La página web www.ikea.com es la herramienta más importante a través de la cual la empresa crea una imagen socialmente aceptable. La página web, de color amarillo y azul reflejo de la entidad, recoge una gran cantidad de información sobre las prácticas de responsabilidad que la empresa lleva a cabo.

La lectura de la historia es reflejo claro de la importancia que IKEA da a la Responsabilidad Social Corporativa, porque la mayoría de los 
acontecimientos destacados en la cronología hacen referencia a acciones que la empresa realizó en beneficio social.

La historia la encontramos en la sección de la página denominada "Acerca de IKEA", donde hay más información sobre la racionalidad societal. Nos comunican las prácticas de responsabilidad llevadas a cabo; colaboración con organizaciones, mejoras para alcanzar la sostenibilidad, programas educativos y sanitarios, información sobre la idea de negocio, las cifras de la entidad, los códigos de conducta y noticias de prensa con las novedades de la empresa. Estas últimas son símbolo de transparencia empresarial, aspecto incluido en la RSC. Asimismo, destaca la subsección de "Preguntas más frecuentes" donde se dedica un apartado exclusivo a preguntas acerca de responsabilidad social y medioambiental, reflejando claramente la importancia que para la empresa tiene que el cliente conozca las actividades desarrolladas en este campo.

La web en sí misma es otra forma de relacionarse y adaptarse a una sociedad que cada vez utiliza más Internet. En el sitio web de IKEA se podrá conocer la empresa, sus productos y comprar sin salir de casa, ahorrando tiempo y dinero. Mientras el cliente conoce los productos IKEA y/o compra encontrara mensajes como "mejorar el día a día de la mayoría de las personas" o "facilitar el trabajo", recordándole la importancia que el individuo tiene para la empresa. Tal es la importancia de la persona que se le concede la posibilidad de opinar, por ejemplo, en la zona de la web dedicada a prensa se invita a ponerse en contacto con la empresa, lo que supone un instrumento de relación con los grupos de interés, permitiendo conocimiento y colaboración, lo mismo que se logra con los ordenadores de sugerencias que hay en los restaurantes de las tiendas.

La palabra colaboración está muy presente en la zona web de "Trabaja en IKEA", estructurada muy adecuadamente para que la sociedad compruebe el compromiso de la entidad. En ese apartado encontramos, un cuestionario de valores y cultura IKEA para que aquellos que quieran trabajar en la empresa puedan comprobar si es el lugar de trabajo idóneo para ellos y, también, una 
descripción de las diferentes áreas de trabajo, para descubrir la que mejor se adapte a las expectativas del aspirante. Importante en la imagen de la empresa es el subapartado de esta sección dedicado a las historias de los colaboradores; resumidas en humildad, formación conjunta, colaboración, flexibilidad, igualdad y entusiasmo; reflejo de la felicidad de los colaboradores con su trabajo.

\section{IKEA en las redes sociales}

Las redes sociales en Internet son un recurso clave en términos empresariales. El crecimiento exponencial en el uso de estas redes, hace que las empresas se vean obligadas a estar presentes en las mismas. El valor en términos estratégicos es máximo. Los clientes están en esas redes, en ellas se crean comunidades que permiten segregar el mercado, un gran potencial que debe aprovecharse.

"Los avances de las tecnologías de la información y de la comunicación han incorporado nuevas herramientas y formas de intermediación e interactividad que están reconfigurando el espacio mediático. Esas relaciones y redes sociales o profesionales establecidas y desarrolladas a través de Internet nos sitúan ante una nueva fase, que algunos califican como postmediática, de una sociedad de servicios aún mucho más acelerada y en la que la atención aparece más segmentada, personalizada, instantánea, diluida, convergente, transparente, flexible, liviana, conversacional, interconectada y abocada a la colaboración, participación y trivialización." (Campos, 2008: 287).

Las redes sociales en Internet son uno de los cambios de los que hablábamos al inicio de este texto, y como ya expresábamos, es necesario que la empresa se adapte a ellos.

IKEA se ha adecuado y está presente en tres de las principales redes: Twitter, Facebook y Youtube. Además, ha creado una red propia: El hogar.de. 
Formar parte de estas las redes es símbolo de cercanía y de interés por la población, premisas básicas en las acciones de RSC.

En Twitter, de manera activa, IKEA lanza mensajes sobre sus productos y campañas, siempre con un enfoque social y con un tono de emotividad. Por ejemplo, si es el día de comienzo del otoño evocará el placer de disfrutar de una tarde en casa, resguardados del frío con las mantas de la nueva colección. En una idea de conocimiento de las personas, de sus deseos y en una preocupación por su bienestar.

En Facebook, procede del mismo modo, aunque juega más con las imágenes. En esta red social, la participación de los usuarios es muy alta, podemos ver mensajes con 3000 'me gusta'. Este dato es reflejo de la difusión que puede llegar a tener un mensaje colgado en Facebook, se alcanzan cuotas máximas.

Youtube recopila videos de los spot publicitarios, de entrevistas acerca de la empresa, de novedades comerciales y de trucos para la decoración del hogar. En todos ellos los protagonistas son las personas, aunque el fin sea la promoción de un nuevo producto, siempre se le dará un enfoque de vivencia, en un modelo empresarial en el que se integra la preocupación social.

La red social creada por IKEA, El hogar.de, permite al usuario crear su propio hogar, no una casa de simples ladrillos, sino un lugar de momentos y vivencias que compartir con el resto de hogares presentes en la red. Se crea una comunidad de hogares en la que no podremos pedirle sal al vecino, pero si una receta para hacer una tarta de manzana o ideas para decorar nuestra casa de cara a la navidad. Es una red diferente creada en torno a los amantes del hogar, público objetivo de la empresa de muebles, esos serán sus principales clientes a los que desea unir, conocer y manifestarles su preocupación por ellos.

\section{Anuncios televisivos de IKEA}

Los vídeos de anuncios colgados en las redes sociales y difundidos en el resto de medios de comunicación, sirven para recordar a la población que la 
empresa consigue crear un país en el que las personas mandan, un país que es la casa de cada uno de nosotros amueblada con los muebles IKEA, utilizando la frase "iVive la República Independiente de tu Casa!", que aparece al final de todos sus anuncios y también en la cabecera de su página web.

El anuncio de 2009 era una melodía "donde caben dos, caben tres, y si caben tres tú también, donde caben dos, caben tres, donde caben dos, caben tres..." con imágenes de los miembros de la familia, las estancias de la casa y los diferentes productos que utilizan los distintos miembros en las estancias del hogar. El spot comienza con un hijo que le dice a su padre "papá creo que voy a tener que volver a casa" y el padre que le canta "donde caben dos, caben tres...", situación que refleja la vivida en muchos hogares como consecuencia de la crisis económica iniciada en esos años. La empresa intenta hacer ver a la sociedad que tiene en cuenta los problemas actuales, a los que se debe combatir con la familia unida (los primeros minutos del anuncio muestran una comida familiar y los siguientes se centran en cada miembro de la unidad familiar) y con IKEA que ayuda en tiempos difíciles a hacer de lo complicado lo sencillo.

\section{Catálogos}

Otra de las herramientas de la empresa son los catálogos. Todos los años en septiembre se lanza el "Catálogo IKEA", que recoge todos los artículos de la colección. A través del catálogo se conoce la empresa, sus productos, y algunas de las acciones sociales que realiza, resumidas junto a los productos.

Además del catálogo IKEA, la empresa lanza otros catálogos; Catálogo Confort, Catálogo Baños, Catálogo Colchones, Catálogo Cocinas, Catálogo Soluciones para TV, Catálogo Armarios, Catálogo Sofás, entre otros; específicos y más reducidos pero en los que también se recogen acciones de fin social.

Las mejoras que se han producido en el Catálogo IKEA forman parte de "Una Lista Sin Fin", porque IKEA trabaja activamente por la producción sostenible. El catálogo fue la primera gran publicación en color del mundo 
impresa en papel totalmente libre de cloro. El objetivo es conseguir que el papel utilizado provenga de bosques con certificado de gestión responsable. Se ha logrado que el catálogo presente un formato más compacto reduciendo el consumo de papel y las necesidades de transporte, disminuyendo la cantidad de emisiones de $\mathrm{CO} 2$ por copia. Cuando se lanza un nuevo catálogo se realizan campañas de recogida de los antiguos para reciclarlo y donar por cada uno recibido $0,50 €$ al fondo destinado a proyectos sociales, contribuyendo a la concienciación de la población en los temas ambientales y sociales y, así también, se recalca la importancia que estas cuestiones tienen para la empresa.

\section{IKEA FAMILY LIVE}

La Revista de decoración IKEA FAMILY LIVE es uno de los mejores ejemplos de la importancia que para IKEA tiene su imagen de marca. La revista recoge diferentes artículos en los que se entremezclan los productos de decoración, las personas, y las actuaciones de la empresa a favor de cuestiones ambientales y sociales. Porque no es solo hacer también hay que comunicar, para que aquellos que demandan que la empresa sea un hecho social puedan dar ventaja competitiva a aquellas entidades que lo son.

\section{Tienda IKEA}

Por último, destacar el papel de las exposiciones de la empresa. La propia tienda sirve a IKEA para recordarle al cliente que no está sólo en una tienda de muebles, que IKEA es mucho más. Para lo que utiliza todos los espacios de la tienda. Con frases para resaltar la importancia de las personas; como la que suele haber en la zona de muebles para niños: "Para las personas más importantes del mundo". IKEA no se aleja de la realidad y desea hacerla más fácil, ejemplo de ello son los pisos piloto de reducidas dimensiones que se pueden visitar en sus tiendas. Asimismo, se hace uso de cárteles en los que resumen proyectos en los que participa la entidad, un ejemplo serían los que hacen referencia al proyecto "Una Tarea Sin Fin" o en los que resalta que sus 
precios son baratos y la razón de que así sea. Los productos también sirven para comunicar, el instrumento son las etiquetas que recogen información de las campañas de mejoras. El paseo por la tienda con basuras diferenciadas para cada producto, el punto de recogida de catálogos o las cajas en las que no se sirven bolsas, nos recuerdan que estamos en una tienda ecológica. Preocupada por temas sociales y medioambientales, recogidos en los catálogos y folletos que se encuentran en toda la tienda.

IKEA se define como una cumplidora de sueños y te lo dice para que no lo olvides y sepas valorarlo.

\section{Conclusiones}

Si algo caracteriza el mundo actual es el proceso de cambio continuado en el que estamos inmersos. Como si el mundo y sus habitantes fuesen un móvil, pasamos de moda casi desde el momento en que nacemos. Las alteraciones nos invaden, no podemos escapar a su fuerza, hacerlo es desaparecer.

Una de esas transformaciones, conocida como Responsabilidad Social Corporativa, ha supuesto un cambio en el modelo de gestión de las instituciones. La RSC es un modelo de integración voluntaria de preocupaciones económicas, sociales y medioambientales en la estrategia institucional. Este concepto se desarrolló en la segunda mitad del siglo XX, y aunque muchos son reacios a su inclusión, ésta se afianza a un ritmo de crecimiento elevado. La RSC se ha convertido en objeto de estudios e inquietud de los gestores institucionales.

En los planteamientos de Responsabilidad Social Corporativa siempre se debe incluir la gestión de la percepción social, es decir, las acciones a desarrollar para lograr que la población asocie valores simbólicos a las entidades. Las instituciones, en respuesta a la sociedad demandante, integraran en sus modelos de negocio (lucrativos o no), la triple vertiente económica, social y medioambiental. Un ejemplo de una acción que podría 
llevar a cabo una institución comprometida, sería incorporar en su plantilla de colaboradores a personas en riesgo de exclusión.

La RSC es respuesta a una demanda de la población, que desea relacionarse con entidades que se preocupen por los mismos asuntos que velan sus sueños. En esa respuesta, la comunicación juega un papel fundamental, porque si la razón de ser de las prácticas de RSC, los grupos de interés, no perciben ese esfuerzo institucional, el trabajo no habrá sido abonado y no tendrá frutos.

Es imprescindible que las instituciones valoren la comunicación en su papel estratégico de difusión de activos intangibles, como lo son las labores de RSC. Una vez concienciadas, deben hacer uso de diferentes herramientas comunicativas para gestionar la percepción social. Entre esas herramientas destacan la página web, las redes sociales, las revistas, los catálogos, los folletos informativos, los anuncios y los lugares de trabajo y/o venta.

En el conocimiento de estas herramientas y en su buena utilización, tomar ejemplo de otras instituciones permitirá alcanzar el éxito buscado. Se debe ver al prójimo como fuente de sabiduría, ya sea para aprender de sus buenas prácticas o de sus fracasos. Este texto ha ido en esa línea, en dar ejemplo a las instituciones de las acciones a desempeñar, basándonos en el caso de una empresa de éxito, IKEA, de un país pionero y líder en materia de responsabilidad social, Suecia.

La clave es adaptarse, conocer el entorno de acción y los grupos de relación, para aprovechar ese conocimiento en desarrollar una gestión adecuada. Dentro de ese entorno y esos grupos, se encuentran otras instituciones que no han de verse como enemigos, sino como modelos de ejemplo, de los que es necesario aprender. En ese aprendizaje y en su puesta en marcha estará el futuro de nuestra institución. Tenemos una tarea pendiente con fecha de entrega de antes de ayer, sirvan estas reflexiones para no retrasar más nuestros deberes. 


\section{Bibliografía}

Cámara de Comercio Sueco Argentina (2010). "Ejemplos actuales de responsabilidad social empresarial (RSE) en el ámbito laboral". Recuperado 4, 11, 2013 de http://www.ccsa.com.ar/RSE Informe.pdf.

Campos Freire, F. (2008). "Las redes sociales trastocan los modelos de los medios de comunicación tradicionales". Revista Latina de Comunicación Social, 63, pp. 287-293. La Laguna (Tenerife): Universidad de La Laguna. Recuperado 4, 11, 2013 de

http://www.ull.es/publicaciones/latina/ 2008/23 34 Santiago/Francisco Campo s.html.

Castro, B. (2007). El auge de la comunicación corporativa. Sevilla: Creative Commons.

Comisión Europea (2001). Libro Verde. Fomentar un marco europeo para la responsabilidad social de las empresas. Bruselas: Comisión de las Comunidades Europeas. Recuperado 4, 11, 2013 de http://www.aeca.es/comisiones/rsc/documentos fundamentales rsc/ue/verde.p df.

Cuesta, M. y Valor, C. (2003). "Responsabilidad social de la empresa. Concepto, medición y desarrollo en España”. Boletín Económico de ICE, № 2755, pp. 7-19.

Kamprad, I. y Torekull, B. (2008). La historia de IKEA: su fundador cuenta los secretos de la empresa que ha entrado en todos los hogares del mundo. Madrid: La esfera de los libros.

IKEA. En www.ikea.com. Recuperado 4, 11, 2013. 
Madrigal Barrón,P.

La comunicación institucional ante el reto...

Marín, F. (2008). Responsabilidad social corporativa y comunicación. Madrid: Fragua.

Putnam, R. D. (ed.) (2003). El declive del capital social. Barcelona: Galaxia Gutenberg.

Swedish Institute (2011). "Suecia lidera con el ejemplo en responsabilidad social corporativa". Corporate Social Responsibility. Recuperado 4, 11, 2013 de http://sweden.se/other-languages/spanish/RSC-high-resolution.pdf. 